\title{
Changing Treatment Paradigm of Type 2 Diabetes
}

\author{
Kyung Yul Hur, M.D., Ph.D. \\ Department of Surgery, Soonchunhyang University Hospital, Seoul, Korea
}

\author{
Received March 20, 2020, Revised March 29, 2020, Accepted April 24, 2020 \\ Corresponding author \\ Kyung Yul Hur \\ Department of Surgery, Soonchunhyang University Hospital, 59 Daesagwan-ro, Yongsan-gu, Seoul 04401, Korea \\ Tel: +82-2-709-9476, Fax: +82-2-795-1682, E-mail: hurusa@hanmail.net \\ ORCID: https://orcid.org/0000-0003-0560-6434
}

This is an Open Access article distributed under the terms of the Creative Commons Attribution Non-Commercial License (http:// creativecommons.org/licenses/by-nc/4.0/) which permits unrestricted non-commercial use, distribution, and reproduction in any

Copyright @ 2020 The Journal of Minimally medium, provided the original work is properly cited.

Invasive Surgery. All rights reserved.

\section{PARADIGM SHIFT IN NATURAL SCIENCE}

Shift your paradigm. We need something creative. Think outside the box. These statements are often included in the inaugural addresses of CEOs or chairmen. I too have used this quote during my own presidential inaugural address. These have been frequently cited in the medical community as well. For example, a PubMed search for the combination 'paradigm' and 'diabetes' displays 2,500 matches. But what exactly is paradigm. And can it be changed easily? The term 'paradigm' was originally used in the field of natural science. It was created and first appeared in 1962, in a book titled 'The Structure of Scientific Revolution' by Thomas Kuhn. But is it possible for a revolution to take place in the field of natural science?

Yes - Paradigm shifts are constantly occurring in the field of natural science. The shift from geocentrism to heliocentrism is a prime example of paradigm shifting. Copernicus's heliocentrism is the astronomical model wherein the solar system planets, including Earth, revolve around the Sun as the central point. Historically, heliocentrism is opposed to Aristotle's geocentrism, which placed the Earth at the center.

Additionally, let us consider underwear as an example to comprehend the paradigm shift in everyday life. The original intention of the underwear was to cover up embarrassing body parts, but current trends are transforming to flaunt the under- wear itself. This drastic transformation of conception is called a paradigm shift. Those who are at the center of a paradigm shift must undergo the tribulation. Copernicus claimed heliocentrism at a time when people believed Earth was the center of the world; hence, his opinion was rejected, and he was persecuted during his lifetime since people were unable to accept that Earth was a part of the world, instead of the center. Similarly, if anyone had tried to switch from covering an underwear to displaying the same,

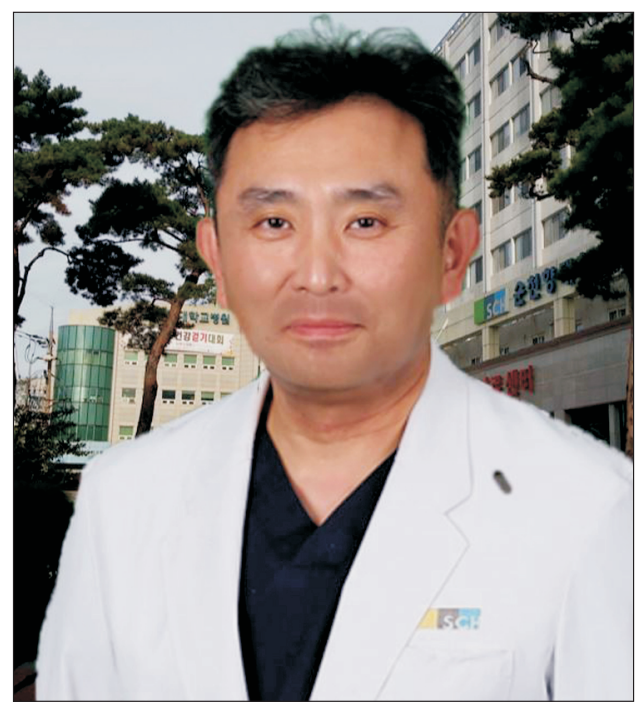


social criticism for that individual would have been tremendous. However, a paradigm in the scientific field is a perspective commonly accepted by every scientist during a period. Given a principle, we interpret everything under the same principle, and that is a paradigm of that moment. If a phenomenon that deviates from the paradigm is observed, an attempt is made to find the reason for the observation error, not the erroneous paradigm. However, if the error cannot be solved and a similar deviation continues, it leads to chaotic confusion. Therefore, a brilliant scientist proposed a new principle that resolves and upturns all these phenomena and error, and the controversy between those who sympathized with the newly suggested principle and those who wished to adhere to the original principle even lead to a dispute. This is the beginning of the shift in paradigm. The conservatives who embrace the existing principle deny and accuse the change, without even trying to understand. The game often favors the conservatives because they usually belong to the higher class of economic, political, and social hierarchy, as compared to the scientist who supports the new theory. Nonetheless, the new paradigm and its followers gain strength and social influence over time, finally settling down after the demise of all conservative supporters, thus allowing the existing theory to be belittled. It should be remembered that all principles are human-made based on existing principles, and therefore cannot be perfect. Hence, a phenomenon varying from the principle will always appear over time, and the paradigm shift will continue. We consider the word revolution to change from corruption, injustice, or inaccuracy, to complete and righteousness. However, nothing is permanent, and revolutions are recurrent over the passage of time. ${ }^{1}$

\section{PARADIGM SHIFT IN TREATMENT OF TYPE 2 DIABETES}

We take it grant for the diabetes is progressive disease with chronically leading to death by inevitable complications.

However, a change has been initiated since some time. The discovery of incretins in the mid-1900s resulted in a paradigm shift that led to hope for improvement in diabetes exacerbation, and finally to a revolutionary revelation in 2000, that surgery could cure diabetes. ${ }^{2}$

With the announcement of the foregut hypothesis in 2005, diabetes was expected to be exterminated within 2 or 3 years; however, it has stagnated for nearly 20 years since then. ${ }^{3}$ To date, the principle of diabetes treatment is that care is the paradigm. If the principle were to shift to cure, it would be a huge transformation in the paradigm. This paradigm shift seemed attainable with the discovery of surgical treatment. However, the likelihood of this paradigm changing is still ongoing, with numerous research undertakings and clinical trials.
Repeating phenomena observed are that once improved, there is a recurrence of diabetes, or after achieving complete remission there are instances of subsequent surgical complications. As a result, there has been an increase in the number of doctors doubting the cure through surgical intervention. ${ }^{4}$

\section{PARADIGM SHIFT IN SURGICAL COMPLICATION}

The concept of surgical complications also belongs to a paradigm shift. Surgeries in the past have often been performed as a last resort for patients who do not respond to any medical treatments. For example, the outcomes of surgery were poor because advanced cancer was the most suitable candidate for surgical treatment. Therefore, the consistent increase of surgical intervention to eradicate the disease has resulted in surgical complications being more fatal, regardless of curability. However, doctors were pardoned, and some were even comforted, for operating on such an extensive scale. Considering these measures, the world transformed into a place where results of surgery were accumulated and systematically analyzed, with a concurrent shift in the concept of complications in general surgery. As the surgical gains and losses of patients can be precisely predicted, and numerous problems have been resolved through the development of various surgical methods and instruments, the paradigm is now shifting toward minimal complications from surgery. ${ }^{5}$ Since surgical treatment for diabetes is not the final unrivaled measure to treat diabetes, metabolic surgery undertaken should guarantee diabetic improvement, and the procedure needs to be safe without adverse sequelae, conferring permanent anti-diabetic effect.

\section{REQUISITES FOR METABOLIC SURGERY}

Surgery to treat diabetes needs to meet the following requisites simultaneously: proven safety, effectiveness, and long-lasting antidiabetic effects. The paradigm in diabetes treatment will not change unless these three requisites take place in synchronicity with the surgery; if not, the surgery itself is nothing but one of the palliative treatments. But what if a surgery that satisfies these triplexes is possible?

The paradigm shift of diabetes has exerted a world-shattering impact. Since rapidly increasing type 2 diabetes is a global issue, a multitude of university scientists and pharmaceutical companies have heavily invested and are involved in the research for diabetes care. Although, if the paradigm is maintained as an incurable disease, upgrading a drug that lowers blood sugar level will be the main focus, and new drugs will be developed to strengthen the effect and minimize any side effects. However, fundamental change begins with a paradigm shift towards cure for diabetes. Primarily, almost every existing research would therefore be- 
come useless, and the direction of the research would switch to solving the fundamental issue. For example, SGLT2 inhibitor, the drugs work by helping the kidney to lower blood glucose level, will gradually wither, and a method to fundamentally remove the problem (such as glucagon receptor knockout) will become active. The debate here is obvious. Considering the population that is currently engaged in the treatment of diabetes with market size of pharmaceutical companies in the global economy, it may create unprecedented economic turmoil.

\section{PERSONAL EXPERIENCE}

I have started surgical intervention to cure for non-obese type 2 diavetes since 2009. ${ }^{6,7}$ Although the effect of the treatment seemed reasonable at the beginning, I started to recognize some gastrointestinal symptoms related to surgery with passing time. I subsequently had to decide whether or not to continue the operating method of 5 years, since discomfort of digestion after surgery is a very critical factor. Meanwhile, being concerned with the mechanism of the applied surgical treatment, I discovered a new fact and devised a surgery plan. Through the new surgical method practiced since 2015 , the outcomes of surgery have been better than expectations. ${ }^{8}$

In its fifth year, many patients are now able to control their blood sugar without relapse or discomfort, and without drugs or insulin. However, this method is a long way from being acknowledged. But the truth is that a paradigm shift always occurs. I know that the diabetes is being cured through this surgery. This is not just a claim, but a fact to be recognized, although I do not know when it will be publicly accepted. Therefore, I cannot predict how much time is needed, if at all it is possible, and whether I will experience a paradigm shift in treatment of type 2 diabetes. However, considering the recent development of SNS and the Internet, there is a possibility of rapid progress, as compared to previous situations. The possible causes of ineffective outcomes of surgery until now is, that if one problem is solved, another problem is created, and the original problem is repeated since both problems originate from the same source, which must therefore be removed and preserved to solve all difficulties. In this case, the duodenum should be excluded totally, while pyloric sphincter needs to be preserved.

\section{CONCLUSION}

One of the most basic and essential features of diabetic surgery is the necessity to maintain the quality of life, but this may not solve the link to recurrence. The possibility and implication of these factors eventually lead to the solution, which was to devise a simple way to maintain the quality of life, and to eliminate relapses. In conclusion, the question of whether a paradigm shift is possible in the field of medicine is possible to answer, but is not easy. Paradigm cannot be changed easily. The change only happens subsequent to numerous demanding works.

\section{ORCID}

Kyung Yul Hur, https://orcid.org/0000-0003-0560-6434

\section{CONFLICT OF INTEREST}

None.

\section{FUNDING}

None.

\section{ACKNOWLEDGMENTS}

None.

\section{REFERENCES}

1) Kuhn TS, Hacking I. The structure of scientific revolutions : 50th anniversary edition. Chicago; London: The University of Chicago Press; 2012.

2) Marks V. The early history of GIP 1969-2000: From enterogastrone to major metabolic hormone. Peptides 2019;122:170155.

3) Patriti A, Facchiano E, Donini A. Effect of duodenal-jejunal exclusion in a non-obese animal model of type 2 diabetes: a new perspective for an old disease. Ann Surg 2004;240:388-389; author reply 389-391.

4) Pinkney JH, Johnson AB, Gale EA. The big fat bariatric bandwagon. Diabetologia 2010;53:1815-1822.

5) Wyld L, Audisio RA, Poston GJ. The evolution of cancer surgery and future perspectives. Nat Rev Clin Oncol 2015;12:115-124.

6) Kim MJ, Park HK, Byun DW, Suh KI, Hur KY. Incretin levels 1 month after laparoscopic single anastomosis gastric bypass surgery in non-morbid obese type 2 diabetes patients. Asian J Surg 2014;37:130137.

7) Kim MJ, Hur KY. Short-term outcomes of laparoscopic single anastomosis gastric bypass (LSAGB) for the treatment of type 2 diabetes in lower BMI (<30 kg/m(2)) patients. Obes Surg 2014;24:1044-1051.

8) Hur KY. Metabolic Outcomes of Surgery for Non-Obese Type 2 Diabetes. J Minim Invasive Surg 2020;23:57-62. 